\title{
Investigations on Three Phase Five Level Cascaded type FCMLI
}

\author{
C.R.Balamurugan ${ }^{1}$, S.P.Natarajan ${ }^{2}$, R.Bensraj $^{3}$ \\ ${ }^{I}$ Department of EEE, Arunai Engineering College,Tiruvannamalai, Tamilnadu, India \\ ${ }^{2}$ Department of EIE, Annamalai University, Chidambaram, Tamilnadu, India \\ ${ }^{3}$ Department of EEE, Annamalai University, Chidambaram, Tamilnadu, India
}

\begin{abstract}
This work presents the comparison of various multicarrier based Pulse Width Modulation (PWM) techniques for the chosen Hbridge type Flying Capacitor Multi Level Inverter (FCMLI). In this paper, a H-bridge type FCMLI is controlled with Sinusoidal PWM (SPWM) technique with Phase Disposition (PD), Phase Opposition and Disposition (POD), Alternative Opposition and Disposition (APOD), Carrier Overlapping (CO), Phase Shift (PS) and Variable Frequency (VF) PWM techniques and the variation of Total Harmonic Distortion (THD) in the output is observed by varying the modulation index. Simulation is performed using MATLAB-SIMULINK. It is observed that sinusoidal reference with PSPWM provides output with relatively low distortion and relatively lower stress on the devices. It is also seen that COPWM strategy is found to perform better since it provides relatively higher fundamental RMS output voltage and relatively lower stress on the devices.
\end{abstract}

Keywords - APOD, CF, CO, FCMLI, PD, PS, POD, THD

\section{INTRODUCTION}

Multilevel inverters are significantly different from the ordinary inverter where only two levels are generated. A group of semiconductor devices are connected in series to one single high voltage switch. Each group of such devices contribute to a step in the output voltage waveform. The steps are increased to obtain an almost sinusoidal waveform. The research on the multilevel inverter technique now focuses on new multilevel topologies based on the existing multilevel topologies. The existing hybrid multilevel topologies utilize the Diode Clamped MultiLevel Inverter (DCMLI) or Flying Capacitor Multi Level Inverter (FCMLI) to replace the H-bridge as the basic module of the Modular Multi Level Inverter (MMLI) in order to reduce the number of the separate DC voltage sources. McGrath and Holmes [1] proposed a sinusoidal PWM of multilevel inverter in over modulation range. Lai and Peng [2] made a detailed survey on multilevel inverters. Corzine et al [3] described various control strategies for cascaded multilevel inverter. Haiwen et al [4] introduced hybrid cascaded multilevel inverter with PWM control method. Jing Zhao et al [5] developed a novel PWM control method for hybrid clamped multilevel inverters. Jinghua and Zhengxi [6] made a research on hybrid modulation strategies based on general hybrid topology of multilevel inverter. Govindaraju and Baskaran [7] proposed optimized hybrid phase disposition PWM control method for multilevel inverters. Zhong et al [8] developed fundamental frequency switching strategies of a seven level hybrid cascaded H-bridge multilevel inverter. Konstantinou et al [9] presented harmonic elimination control of a five level DC-AC cascaded H-bridge hybrid inverter.
Khoucha et al [10] introduced hybrid cascaded $\mathrm{H}-$ bridge multilevel inverter for induction motor drive applications. Sepahvand et al [11] presented a hybrid multilevel inverter with both staircase and PWM switching schemes. Satyanarayanan et al [12] developed hybrid algorithm based vector controlled induction motor drive to achieve superior waveform quality. This literature survey reveals few papers only on various FCMLI and hence this work presents a novel approach for controlling the harmonics of output voltage of chosen $\mathrm{H}$ bridge type FCMLI employing sinusoidal switching strategies. Simulations are performed using MATLABSIMULINK. Harmonics analysis and evaluation of performance measures for various modulation indices have been carried out and presented.

\section{MulTiLeVEL INVERTER}

For research on multilevel inverter topologies, a preferred multilevel inverter topology shall have the following characteristics:

(i) The level is easy to extend

(ii) The number of the separate DC sources is few

iii) There is no voltage balance problem

iv) It has a modular structure

This paper presents a general multilevel hybrid topology through research on several basic multilevel topologies and introduces a few controllable degrees of freedom in the general hybrid topology. No matter what changes occur in the mentioned hybrid topologies, they can be resulted in change and combination of the degrees of freedom, which expand the topology collection of multilevel inverter. All the cascaded topologies are unified through introduction of the degrees of freedom in the general multilevel hybrid topology. Based on research on 
IOSR Journal of Engineering

May. 2012, Vol. 2(5) pp: 1056-1063

hybrid topologies and multicarrier SPWM applied to multilevel inverter, the paper makes a deep study on various modulation strategies applied to hybrid topologies.

Fig. 1 shows a configuration of the three phase five level $\mathrm{H}$ bridge type FCMLI. The concept of this inverter is based on connecting $\mathrm{H}$ bridge inverters in series to get a sinusoidal voltage output. The output voltage is the sum of the voltage that is generated by each cell. The number of output voltage levels are $2 n+1$ where $n$ is the number of cells. The switching angles can be chosen in such a way that the THD is minimized. The output voltage obtained from FCMLI cascade is $\mathrm{E} / 2$. An $n$ level cascaded H-bridge multilevel inverter needs 2(n-1) switching devices Similarly for FCMLI cascaded 2(n-1) switching devices are used. The gate signals for chosen five level cascaded type FCMLI are simulated using MATLAB-SIMULINK. The gate signal generator developed is tested for various values of modulation index $\mathrm{m}_{\mathrm{a}}$ and for various PWM strategies. Fig.2 shows a sample SIMULINK developed for PDPWM technique. The simulation results presented in this paper in the form of the outputs of the chosen FCMLI cascaded are compared and evaluated.

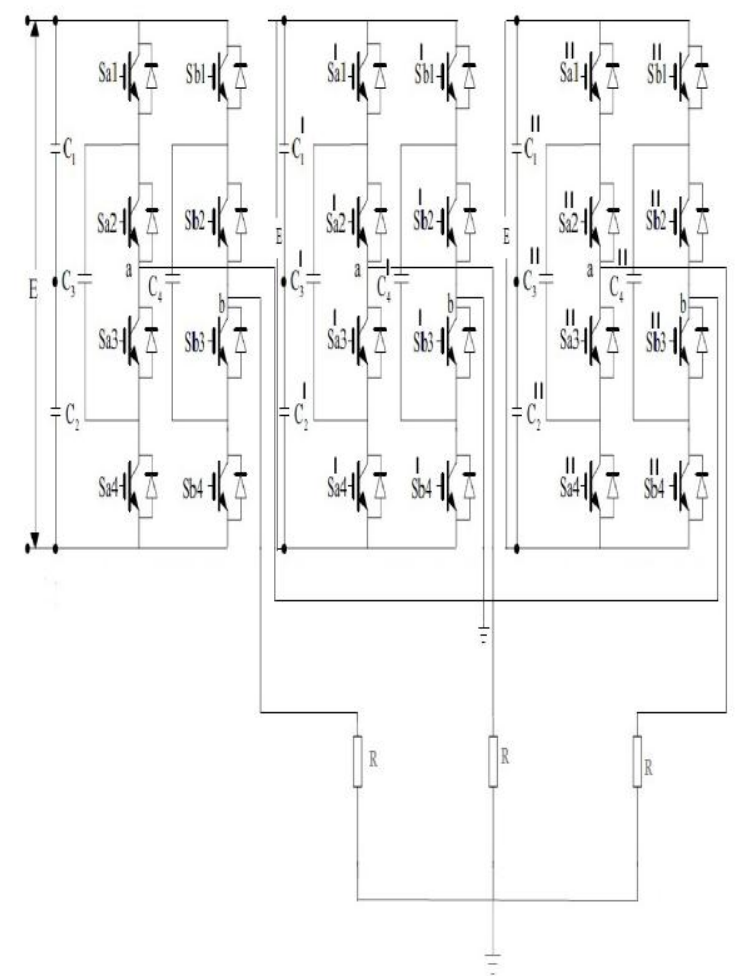

Fig. 1 A three phase five level H-bridge type FCMLI

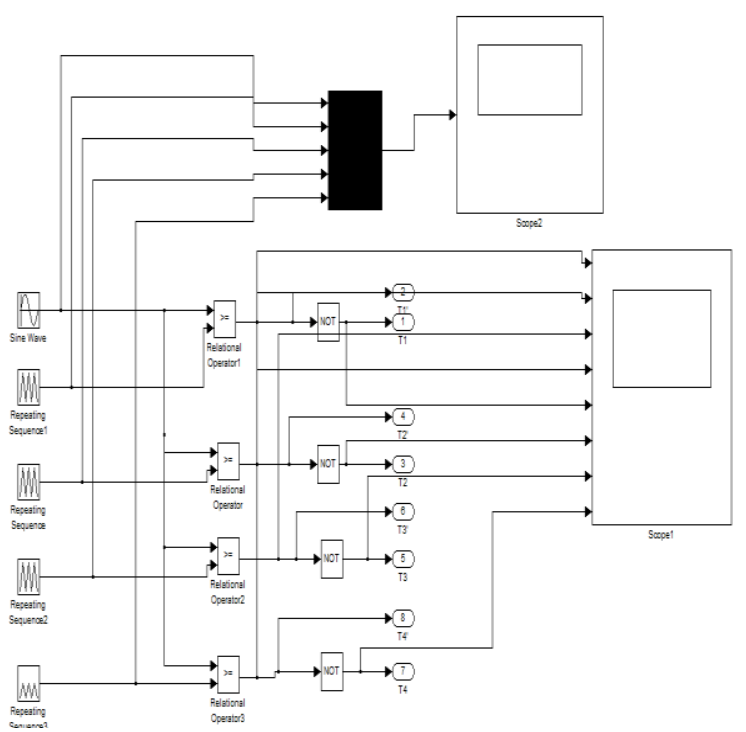

Fig. 2 Sample PWM generation logic using SIMULINK developed for PDPWM technique

\section{Modulation STRATEgies}

Development of concerns PWM control strategies the development of techniques to reduce the THD of the current. It is generally recognized that increasing the switching frequency of the PWM pattern reduces the lower frequency harmonics by moving the switching frequency carrier harmonics and associated sideband harmonics further away from the fundamental frequency component. The modulating/reference wave of multilevel carrier based PWM strategies can be sinusoidal. In general for a five level inverter four carriers are needed for symmetrical multilevel inverter. As far as the particular reference wave is concerned, there is also multiple Control Freedom Degree (CFD) including frequency, amplitude, phase angle of the reference wave. This paper focuses on hybrid power circuit with sinusoidal reference and triangular carrier which have been used in chosen three phase cascaded type FCMLI. The following strategies are employed in this study which have used the intersection of a sine wave with a triangular wave to generate firing pulses.

The amplitude modulation index for $\mathrm{PD} / \mathrm{POD} / \mathrm{APOD} / \mathrm{VFPWM}=2 \mathrm{~A}_{\mathrm{m}} /(\mathrm{m}-1) \mathrm{A}_{\mathrm{c}}$.

The amplitude modulation index for PSPWM $=\mathrm{A}_{\mathrm{m}} /\left(\mathrm{A}_{\mathrm{c}} / 2\right)$.

The amplitude modulation index for COPWM $=\mathrm{A}_{\mathrm{m}} /(\mathrm{m} / 4) \mathrm{A}_{\mathrm{C}}$.

$\mathrm{m}_{\mathrm{f}}=\mathrm{f}_{\mathrm{c}} / \mathrm{f}_{\mathrm{m}}$

where

$\mathrm{f}_{\mathrm{c}}$ - Frequency of the carrier signal

$\mathrm{f}_{\mathrm{m}}-$ Frequency of the reference signal

$A_{m}$-Amplitude of the reference signal 
$\mathrm{A}_{\mathrm{c}}$ - Amplitude of the carrier signal

$\mathrm{m}-$ number of levels.

\section{III. (a) APOD strategy}

As can be seen in the Fig. 3 for a five level inverter a total of four carrier waves are used.

i) They are arranged in such a manner that each carrier is out of phase with its neighbor by 180 degrees.

ii) The converter switches to $+V_{d c} / 2$ when the sine wave is higher than all carrier.

iii) The converter switches to $+V_{d c} / 4$ when the sine wave is lower than the uppermost carrier waveform and greater than all other carrier.

iv) The converter switches to 0 when the sine wave is lower than the two uppermost carrier waveform and greater than two lowermost carrier.

v) The converter switches to $-V_{d c} / 4$ when the sine wave is higher than the lowermost carrier waveform and lesser than all other carriers.

vi) The converter switches to $-V_{d c} / 2$ when the sine wave is lesser than all carrier.

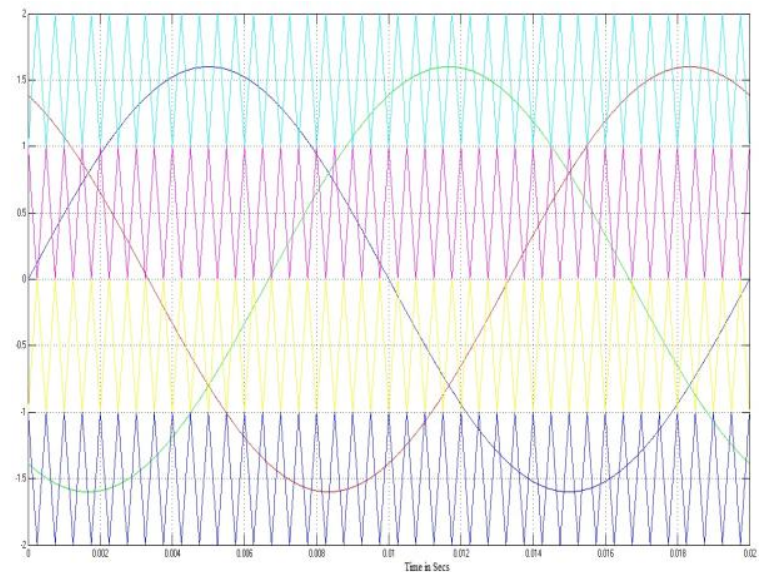

Fig. 3 Carrier arrangement for APODPWM strategy

$$
\left(\mathrm{m}_{\mathrm{a}}=0.8 \text { and } \mathrm{m}_{\mathrm{f}}=40\right)
$$

\section{III. (b) POD strategy}

a) Four carrier waveforms are arranged so that all carrier waveforms above zero are in phase and are 180 degrees out of phase with those below zero.

b) The converter is switched to $+V_{\mathrm{dc}} / 2$ when the sine wave is higher than both carrier waveforms.

c) The converter switches to $+V_{\mathrm{dc}} / 4$ when the sine wave is lower than the uppermost carrier waveform and greater than all other carrier.

d) The converter is switched to zero when the sine wave is greater than the lower carrier waveform but less than the upper carrier waveform. e) The converter switches to $-V_{d c} / 4$ when the sine wave is higher than the lowermost carrier waveform and lesser than all other carriers.

f) The converter is switched to $-V_{d c} / 2$ when the sine wave is less than both carrier waveforms.

In the PWM scheme there are four triangles, upper two triangle have magnitude from 2 to 0 and the lower two triangles exist from 0 to -2 and these two triangle waveforms are out of phase.

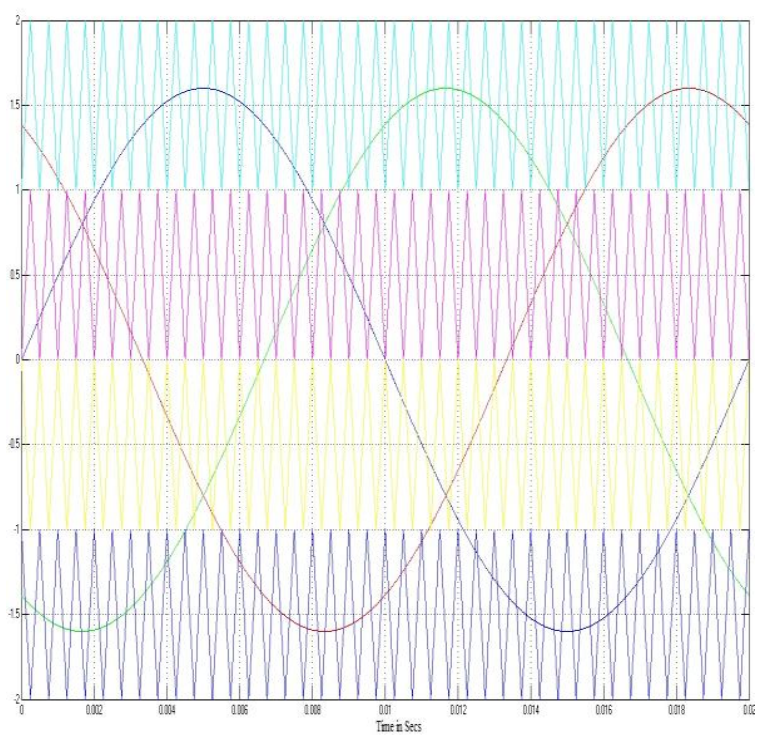

Fig. 4 Carrier arrangement for PODPWM strategy

$$
\left(\mathrm{m}_{\mathrm{a}}=0.8 \text { and } \mathrm{m}_{\mathrm{f}}=40\right)
$$

\section{III. (c) PD strategy}

The rules for phase disposition method for a multilevel inverter are

a) 4 carrier waveforms in phase are arranged.

b) The converter is switched to $+\mathrm{V}_{\mathrm{dc}} / 2$ when the sine wave is greater than both carriers.

c) The converter switches to $+V_{\mathrm{dc}} / 4$ when the sine wave is lower than the uppermost carrier waveform and greater than all other carriers.

d) The converter is switched to zero when sine wave is lower than upper carrier but higher than the lower carrier .

e)The converter switches to $-V_{d c} / 4$ when the sine wave is higher than the lowermost carrier waveform and lesser than all other carriers.

f) The converter is switched to $-V_{d c} / 2$ when the sine wave is less than both carrier waveforms.

As can be seen from the Fig.5 in the PWM scheme there are four triangles, the upper two triangles ranges from 2 to 0 and the lower two triangle ranges from 0 to -2 . 


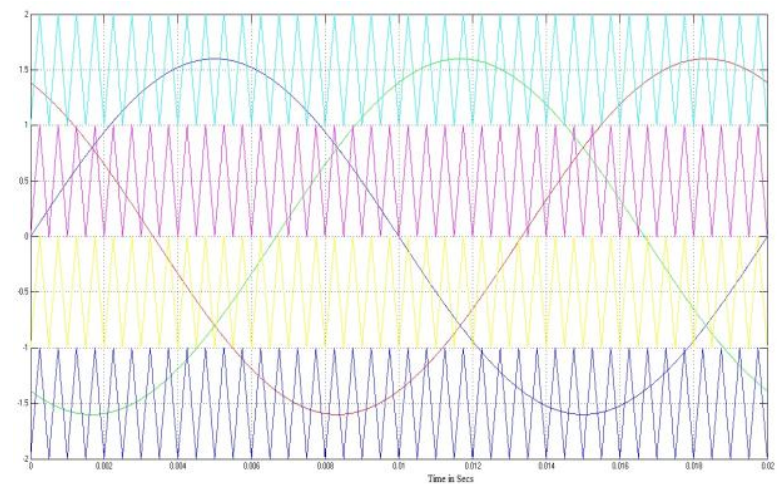

Fig. 5 Carrier arrangement for PDPWM strategy

$$
\left(\mathrm{m}_{\mathrm{a}}=0.8 \text { and } \mathrm{m}_{\mathrm{f}}=40\right)
$$

\section{III. (d) Carrier Overlapping (CO) strategy}

For an m-level inverter using carrier overlapping technique, m-1 carriers with the same frequency $\mathrm{f}_{\mathrm{c}}$ and same peak-to-peak amplitude $\mathrm{A}_{\mathrm{c}}$ are disposed such that the bands they occupy overlap each other; the overlapping vertical distance between each carrier is $A_{c} / 2$. The reference waveform has amplitude of $A_{m}$ and frequency of $\mathrm{f}_{\mathrm{m}}$ and it is centered in the middle of the carrier signals. The reference wave is continuously compared with each of the carrier signals. If the reference wave is more than a carrier signal, then the active devices corresponding to that carrier are switched on. Otherwise, the devices switch off.

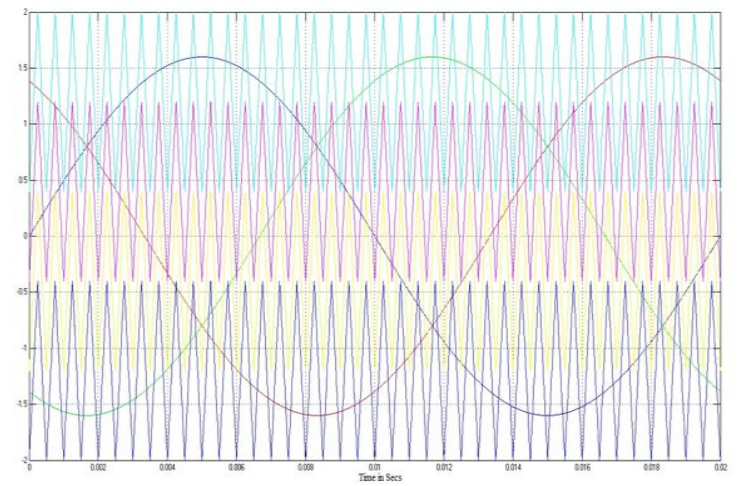

Fig. 6 Carrier arrangement for COPWM strategy

$$
\left(\mathrm{m}_{\mathrm{a}}=0.8 \text { and } \mathrm{m}_{\mathrm{f}}=40\right)
$$

\section{III. (e) VF strategy}

The number of switchings for upper and lower devices of chosen MLI is much more than that of intermediate switches in PDPWM using constant frequency carriers. In order to equalize the number of switchings for all the switches, variable frequency PWM strategy is used as illustrated in which the carrier frequency of the intermediate switches is properly increased to balance the number of switchings for all the switches.

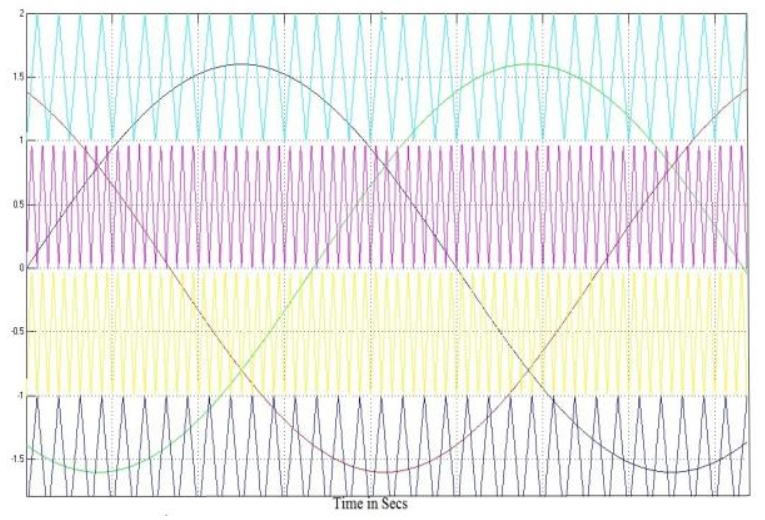

Fig. 7 Carrier arrangement for VFPWM strategy

$$
\left(\mathrm{m}_{\mathrm{a}}=0.8 \text { and } \mathrm{m}_{\mathrm{f}}=40\right)
$$

\section{III. (f) PS strategy}

The phase shift multicarrier PWM technique uses four carrier signals of the same amplitude and frequency which are shifted by 90 degrees to one another to generate the five level inverter output voltage.

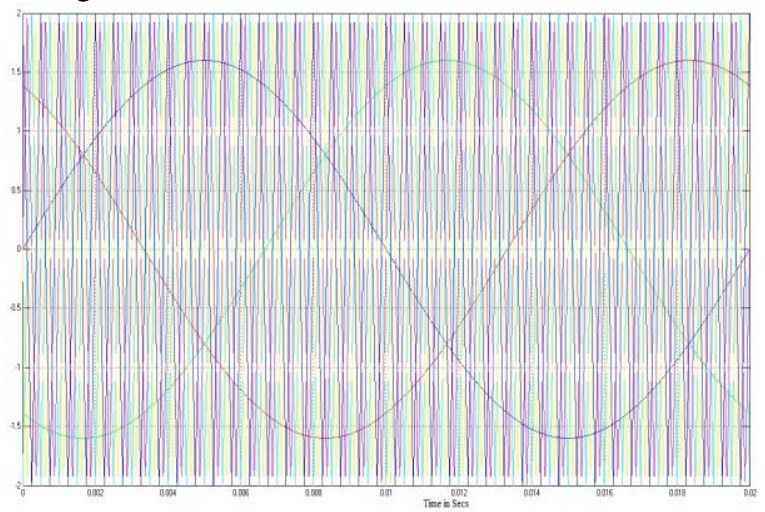

Fig.8 Carrier arrangement for PSPWM strategy

$$
\left(\mathrm{m}_{\mathrm{a}}=0.8 \text { and } \mathrm{m}_{\mathrm{f}}=40\right)
$$

\section{Simulation Results}

The cascaded type FCMLI is modeled in SIMULINK using power system block set. Switching signals for FCMLI are developed using bipolar PWM techniques discussed previously. Simulation is performed for different values of $\mathrm{m}_{\mathrm{a}}$ ranging from $0.6-1$. The corresponding \% THD values are measured using FFT block and they are shown in Table 1 . Table 2 displays the $\mathrm{V}_{\mathrm{RMS}}$ of fundamental of inverter output for same modulation indices. Figs 9-20 show the simulated output voltage of FCMLI and the corresponding FFT plots with above strategies but for only one sample value of $\mathrm{m}_{\mathrm{a}}=0.8$. Fig. 9 shows the five level output voltage generated by APOD strategy 
IOSR Journal of Engineering

May. 2012, Vol. 2(5) pp: 1056-1063

and its FFT plot is shown in Fig.10. From Fig.10 it is observed that the APOD strategy produces significant $35^{\text {th }}$ and $37^{\text {th }}$ harmonic energy. Fig. 11 shows the five level output voltage generated by POD strategy and its FFT plot is shown in Fig.12. From Fig. 12 it is observed that the POD produces significant $33^{\text {rd }}$ and $35^{\text {th }}$ harmonic energy. Fig. 13 shows the five level output voltage generated by PD strategy and its FFT plot is shown in Fig.14. From Fig.14 it is observed that the PD strategy produces significant $30^{\text {th }}, 32^{\text {nd }}$, $36^{\text {th }}$ and $38^{\text {th }}$ harmonic energy. Fig. 15 shows the five level output voltage generated by $\mathrm{CO}$ strategy and its FFT plot is shown in Fig.16. From Fig.16 it is observed that the $\mathrm{CO}$ strategy produces significant $3^{\text {rd }}$ and $38^{\text {th }}$ harmonic energy.

Fig.17 shows the five level output voltage generated by VF strategy and its FFT plot is shown in Fig. 18. From Fig. 18 it is observed that the VF strategy produces significant $34^{\text {th }}$ and $38^{\text {th }}$ harmonic energy. Fig.19 shows the five level output voltage generated by PS strategy and its FFT plot is shown in Fig.20. From Fig. 20 it is observed that the PS strategy does not produce significant harmonic energy. The following parameter values are used for simulation: $\mathrm{V}_{\mathrm{DC}}=440 \mathrm{~V}, \mathrm{f}_{\mathrm{c}}=2 \mathrm{KHz}$ and $\mathrm{R}(\mathrm{load})=100 \mathrm{ohms}$.

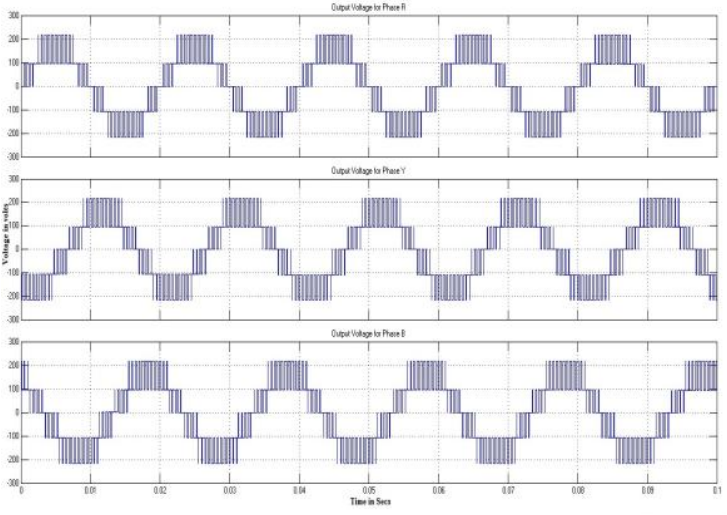

Fig.9 Output voltage generated by APODPWM strategy

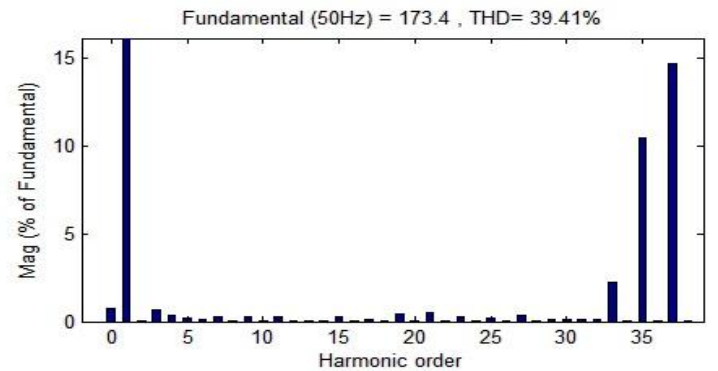

Fig.10 FFT plot for output voltage of APODPWM strategy

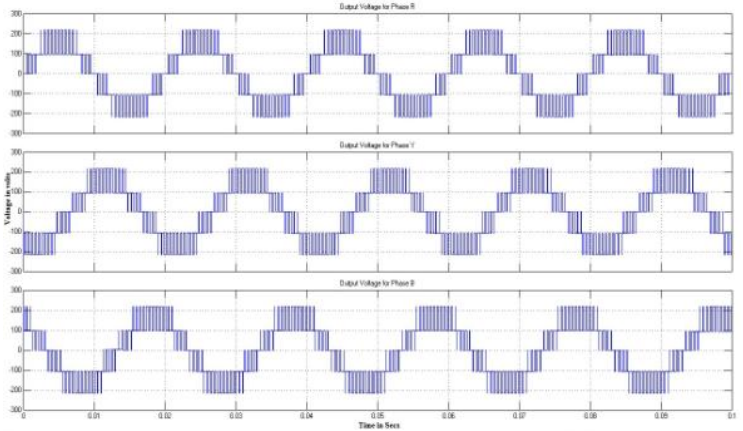

Fig.11 Output voltage generated by PODPWM strategy

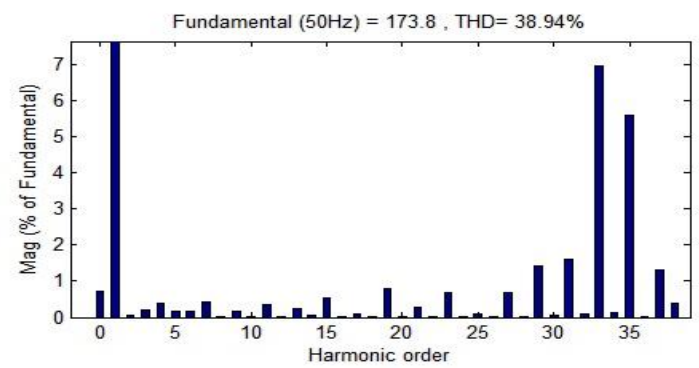

Fig.12 FFT plot for output voltage of PODPWM strategy

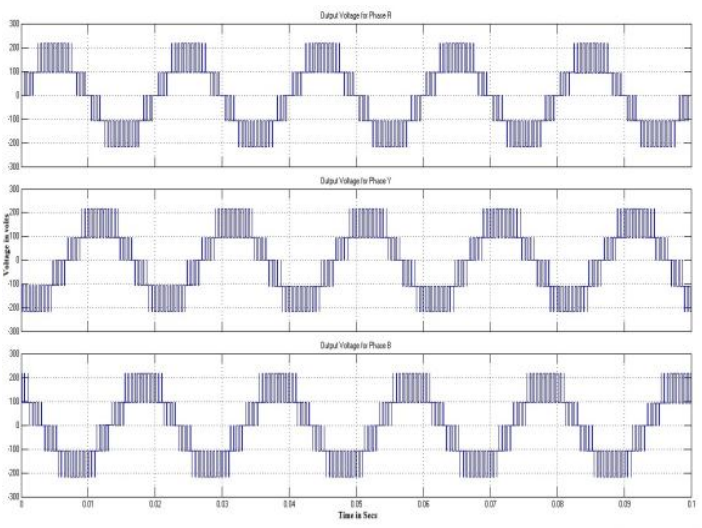

Fig.13 Output voltage generated by PDPWM strategy

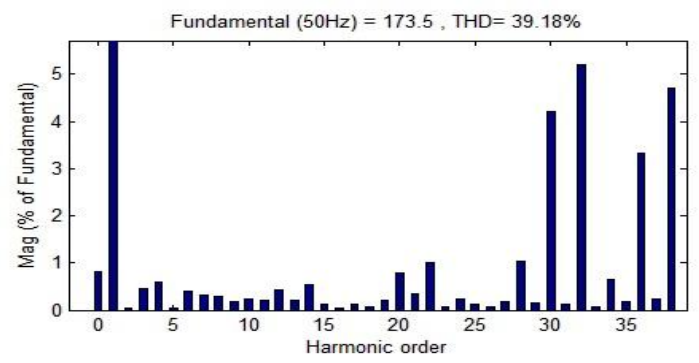

Fig.14 FFT plot for output voltage of PDPWM strategy 
IOSR Journal of Engineering

May. 2012, Vol. 2(5) pp: 1056-1063

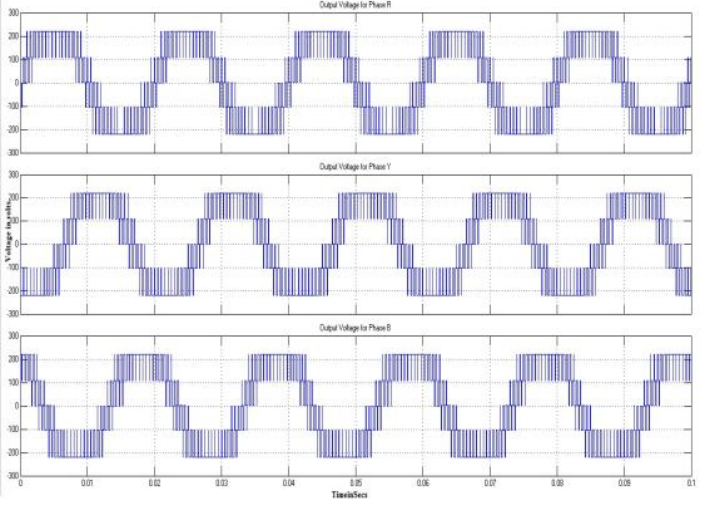

Fig.15 Output voltage generated by COPWM strategy

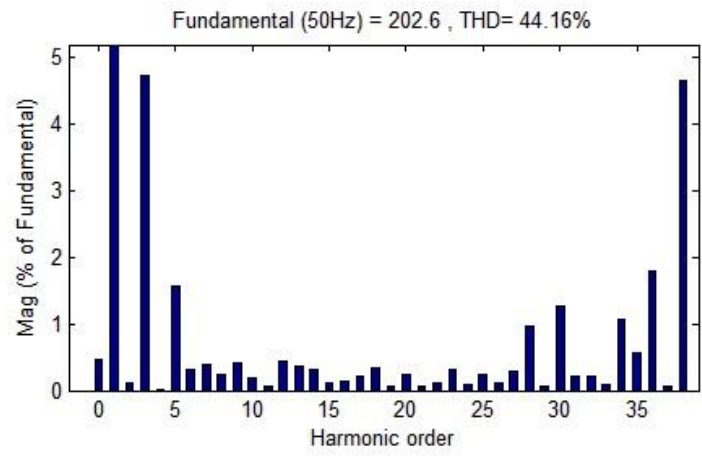

Fig.16 FFT plot for output voltage of COPWM strategy

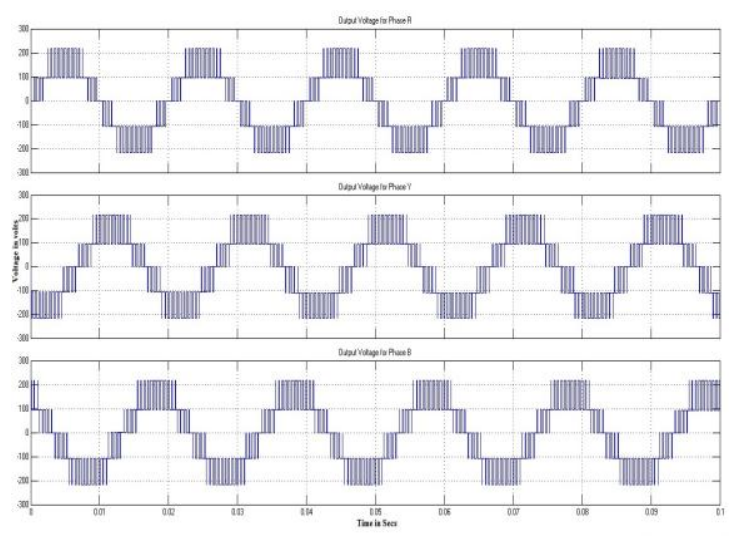

Fig. 17 Output voltage generated by VFPWM strategy

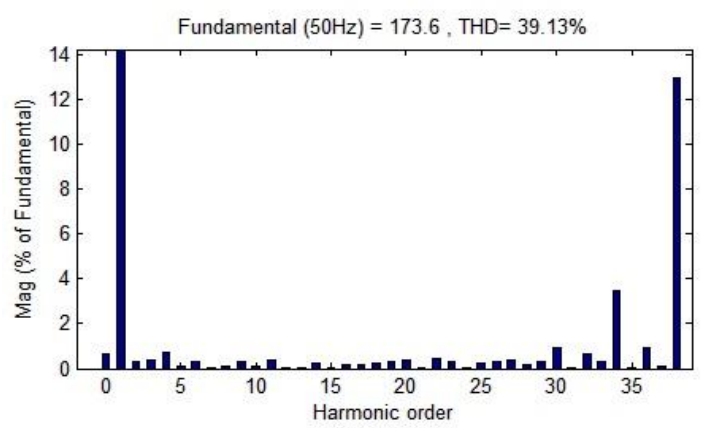

Fig.18 FFT plot for output voltage of VFPWM strategy

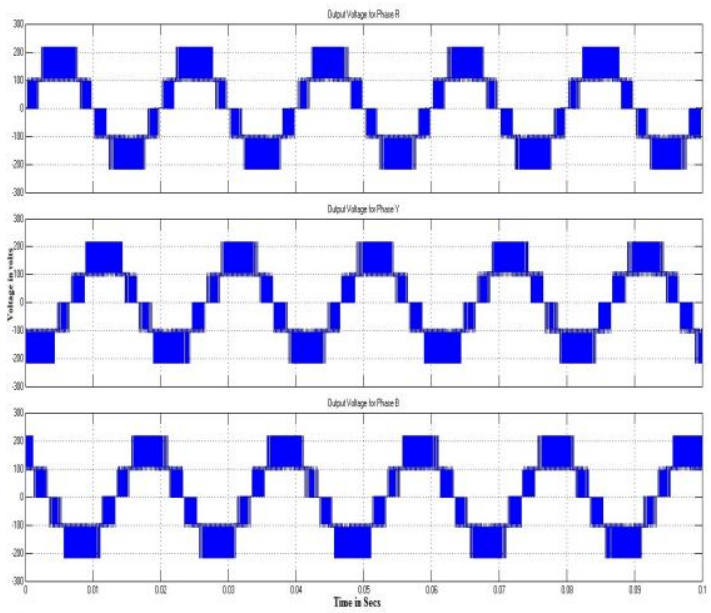

Fig.19 Output voltage generated by PSPWM strategy

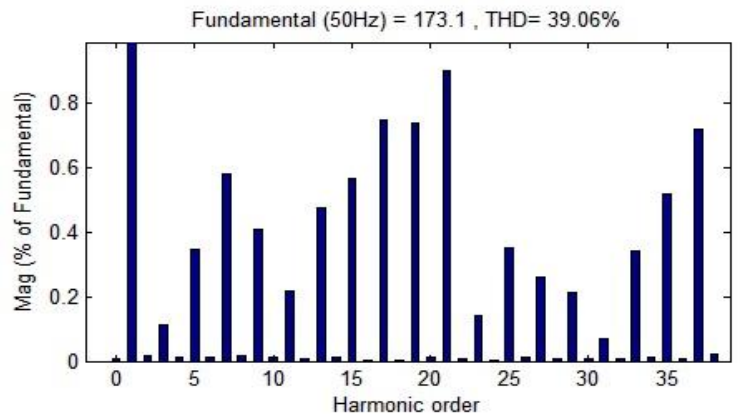

Fig.20 FFT plot for output voltage of PSPWM strategy

Table-1 \% THD for different modulation indices

\begin{tabular}{|c|c|c|c|c|c|c|}
\hline $\mathbf{m}_{\mathbf{a}}$ & $\mathbf{P D}$ & POD & APOD & CO & VF & PS \\
\hline 1 & 27.41 & 27.33 & 27.92 & 32.31 & 27.44 & 27.55 \\
\hline 0.9 & 34.24 & 34.14 & 34.65 & 38.84 & 34.1 & 33.42 \\
\hline 0.8 & 39.18 & 38.94 & 39.41 & 44.16 & 39.13 & 39.06 \\
\hline 0.7 & 42.9 & 42.71 & 42.97 & 55.44 & 43.31 & 42.22 \\
\hline 0.6 & 45.02 & 45.07 & 44.95 & 66.62 & 45.06 & 44.91 \\
\hline
\end{tabular}


IOSR Journal of Engineering

May. 2012, Vol. 2(5) pp: 1056-1063

Table-2 $\mathrm{V}_{\mathrm{RMS}}$ (fundamental) for different modulation indices

\begin{tabular}{|c|c|c|c|c|c|c|}
\hline $\mathbf{m}_{\mathbf{a}}$ & PD & POD & APOD & CO & VF & PS \\
\hline 1 & 154.4 & 154.4 & 154.2 & 157.8 & 154.4 & 154.5 \\
\hline 0.9 & 138.6 & 138.6 & 138.4 & 144 & 138.6 & 138.8 \\
\hline 0.8 & 122.7 & 122.9 & 122.6 & $\mathbf{1 2 8 . 9}$ & 122.8 & 122.4 \\
\hline 0.7 & 106.7 & 106.5 & 106.7 & 110.5 & 106.4 & 107.1 \\
\hline 0.6 & 90.86 & 90.66 & 90.91 & 91.01 & 91.06 & 90.11 \\
\hline
\end{tabular}

Table-3 Crest factor for different modulation indices

\begin{tabular}{|c|c|c|c|c|c|c|}
\hline $\mathbf{m}_{\mathbf{a}}$ & $\mathbf{P D}$ & $\mathbf{P O D}$ & APOD & $\mathbf{C O}$ & $\mathbf{V F}$ & PS \\
\hline 1 & 1.41386 & 1.41386 & 1.414397 & 1.414449 & 1.415155 & 1.412945 \\
\hline 0.9 & 1.414141 & 1.414141 & 1.414017 & 1.414583 & 1.415584 & 1.412104 \\
\hline 0.8 & 1.414018 & 1.414158 & 1.414356 & 1.571761 & 1.409609 & 1.418301 \\
\hline 0.7 & 1.413308 & 1.415023 & 1.414246 & 1.413575 & 1.422932 & 1.405229 \\
\hline 0.6 & 1.414264 & 1.414075 & 1.414586 & 1.41413 & 1.399078 & 1.429364 \\
\hline
\end{tabular}

Table-4 Form factor for different modulation indices

\begin{tabular}{|c|c|c|c|c|c|c|}
\hline $\mathbf{m}_{\mathbf{a}}$ & PD & POD & APOD & CO & VF & PS \\
\hline 1 & 199.32 & 175.5 & 174.47 & 10.24 & 28343.42 & 140.61 \\
\hline 0.9 & 150.76 & 128.09 & 127.44 & 7.44 & 11433.27 & 151.49 \\
\hline 0.8 & 86.71 & 98.08 & 98.15 & 6.42 & 12578.35 & 111.94 \\
\hline 0.7 & 105.74 & 77.11 & 76.54 & 4.07 & 11028.73 & 87.35 \\
\hline 0.6 & 75.9 & 61.92 & 61.71 & 2.99 & 11576.31 & 64.12 \\
\hline
\end{tabular}

\section{Conclusion}

It is observed from Table 1 PSPWM technique provides output with relatively low distortion. COPWM strategy is found to perform better since it

\section{REFERENCES}

[1] B.P.McGrath and D.G. Holmes, Sinusoidal PWM of Multilevel Inverters in the Overmodulation Region, IEEE Transactions on Industrial Applications, Vol.3, No.7, 2002, pp.574-582.

[2] J.S.Lai and F.Z.Peng, Multilevel Inverters A Survey of Topologies, Controls, and Applications, IEEE Transactions on Industrial Electronics, Vol.49, No.4, 2002, pp.724-738.

[3] Keith A. Corzine, Mike W. Wielebski, Fang Z. Peng and Jin Wang, Control of Cascaded provides relatively higher fundamental RMS output voltage (Table 2) and also relatively lower stress on the devices. Table 3 shows crest factor. Next table 4 provides FF for all modulation indices.

Multilevel Inverter, IEEE Transactions on Power Electronics, Vol.19, No.3, 2004, pp.732-738.

[4] Haiwen Liu, Leon M.Tolbert, Surin Khomfoi, Burak Ozpineci and Zhong Du, Hybrid Cascaded Multilevel Inverter with PWM Control Method, IEEE Conf. Rec: 978-1-42441668-4/08, 2008, pp.162-166.

[5] Jing Zhao, Xiangning He and Rongxiang Zhao, A Novel PWM Control Method for HybridClamped Multilevel Inverters, IEEE 
Transactions on Industrial Electronics, Vol.57, No.7, 2010, pp.2365-2373.

[6] Zhou Jinghua and Li Zhengxi, Research on Hybrid Modulation Strategies Based on General Hybrid Topology of Multilevel Inverter, International Symposium on Power Electronics Electrical Drives, Automation \& Motion, Rec: 978-1-4244-1664-6, 2008, pp.784-788.

[7] C.Govindaraju and K.Baskaran, Optimized Hybrid Phase Disposition PWM Control Method for Multilevel Inverter, International Journal of Recent Trends in Engineering, Vol.1, No.3, 2009, pp.129-134.

[8] Zhong Du, Leon M. Tolbert, Burnk Ozpineci and John N. Chiasson, Fundamental Frequency Switching Strategies of a Seven Level Hybrid Cascaded H-Bridge Multilevel Inverter, IEEE Transactions on Power Electronics, Vol.24, No.1, 2009, pp.25-33.

[9] Georgious S. Konstantinou, Sridhar R.Pulikanti and Vassilios G. Agelidis, Harmonic Elimination Control of a Five-Level DC-AC Cascaded H-bridge Hybrid Inverter, $2^{\text {nd }}$ IEEE International Symposium on Power Electronics for Distributed Generation Systems, 2010, pp.352-357.
[10] Farid Khoucha, Soumia Mouna Lagoun, Khoudir Marouani, Abdelaziz Kheloui and Mohamed Ei Hachemi Benbouzid, Hybrid cascaded H-Bridge Multilevel Inverter Induction Motor Drive Direct Torque Control For Automotive Applications, IEEE Transactions on Industrial Electronics, Vol.57, No.3, 2010, pp.892-899.

[11] Hossein Sepahvand, Mostafa Khazraei, Mehdi Ferdowsi and Keith Corzine, A Hybrid Multilevel Inverter with Both Staircase and PWM Switching Schemes, IEEE Conf. Rec: 978-1-4244-5287-3/10, 2010, pp.4364-4367.

[12] K.Satyanarayana, J.Amarnath and A.Kailasa Rao, Hybrid PWM Algorithm Based Vector Controlled Induction Motor Drive to Achieve Superior Waveform Quality, International Journal of Engineering \& Advanced Technology(IJEAT), ISSN:2249-8958, Vol.1, No.2, 2011, pp.56-63. 